maintaining them because of the inter-dependency between the mainstream and the margins. Hinted at within the study are possibilities which, if developed further, might have helped Murray to find a theoretical discourse equal to her careful and always illuminating empirical data. For example, Robert Darnton's 'communications circuit' is discussed in the Introduction, found wanting and not returned to again, except in passing comments. Similarly, remarks about capitalism's amazing capacity to appropriate the oppositional underpins her exploration of mainstream publishing and feminist bestsellers but is not foregrounded. I wondered, at times, whether Pierre Bourdieu's concept of cultural fields might have helped Murray find a way of mapping feminist publishing that would recognize the opposing forces she writes of while also accommodating the endlessly shifting play of distinction.

Murray's Afterword looks to the future, to a period when, as she says, both terms, 'feminist' and 'publishing', are facing uncertain times. As she rightly indicates, it is too precipitate to discount print in favour of digital technology when women's access to print has been so recent and hard won, when there is clearly much still to be said about women's publishing history and when the book is, anyway, showing itself to be a highly resilient medium. Bringing into relation digital and book technologies, Murray ends with a series of strategies for the survival of feminist publishing and the interesting suggestion that feminism's focus should be on intellectual property which would manifest itself in a variety of media. Hence, returning to Woolf and her printing press, Murray concludes that the emphasis in these early years of the 21 st century should be more on controlling the message than the medium. Certainly Murray's 'message' is one that needs to be heard. The academic initiative in feminist publishing, which Murray discusses in Chapter 3, rapidly took a theoretical turn and feminists were in the curious position of theorizing gender with scant consideration of the political meanings of the medium, processes and institutional contexts in which their words were being produced. Murray has provided a very necessary corrective.

doi:10.1057/palgrave.fr. 9400333

Mary Eagleton

\title{
Venus on wheels: two decades of dialogue on disability, biography, and being female in America
}

Gelya Frank; University of California Press, Berkeley, CA, 2000, ISBN 0-520-21715-2, £31.50 (hbk), ISBN 0-520-21716-0, £12.50 (pbk)

Gelya Frank's book tells us not only a story of her research journey in writing a cultural biography of Diane DeVries, 'a woman born with all the physical and 
mental equipment she would need to live... - except arms and legs' (p. 1), but also of a 20 -year dialogue between two women, Diane and Gelya, throughout this journey.

The introduction of the book begins with Frank's stunning description of her impressions of DeVries at their first meeting in a cultural anthropology class. These first impressions strongly projected Frank's assumptions and prejudices, hardly unique to her, on disabled women being 'asexual' and 'dependent'. They would be proved wrong shortly after they started to work together. It was perhaps her first reflection on these impressions that inspired Frank to write a cultural biography, which 'is a synthesis of ethnographic and life history methods' (p. 3), so as to enhance her understanding of both DeVries' life and the culture in which her life story as a 'disabled woman' was constructed. The cultural biography of DeVries draws on diverse sources of data, including her life story as told in formal interviews with Frank, documents written by DeVries such as her letters and unpublished autobiography, her clinical records, interviews with key persons in her life, informal conversations, Frank's firsthand observations, and secondary data such as films and ethnographies. This diversity helps Frank to expand her interpretative horizons as a cultural biographer.

Frank articulates historicism into this cultural biography as she aims to write DeVries' life as 'a woman with a disability in relation to dominant cultural discourses and social practises affecting people with disabilities in the United States during her lifetime' (p. 205). She makes a comprehensive discussion on changing cultural, political and institutional discourses on the meaning of disability and gender in American society during two decades, which enables her to make a deeper analysis of the shifts in DeVries' life. Frank's analysis highlights the dominance of some discourses. She particularly wants to understand why and in which ways those discourses are dominant in DeVries' life. Frank's interpretation of DeVries' biography in the context of changing American discourses and practices guides us to a better understanding of DeVries' resistance to dominant images, prejudices and practices about disabled women.

For me, the most striking point in Frank's cultural biography is her self-reflection on her methodology 'in action as a source of primary data, including the effects of power and personal factors such as the mirror phenomenon' (p. 22). She includes her personal research narrative into her analysis. Frank's reflexive investigation of the meanings she attaches to DeVries' disability transforms her initial focus on academic questions about DeVries into a new understanding of her life. She articulates DeVries' self-understanding into the analysis at this new phase. Her systematic self-reflection throughout their long-term collaboration enables Frank to discover new horizons both in her research and in her 'self'. Her 
analysis of her position as an able-bodied researcher who attempts to understand the life of someone with disability drives Frank to a new journey of self-examination where she uncovers her own invisible disabilities.

When I started to read this book, one of the first questions in my mind was about the power relations between the two women in such a long collaboration in which crossing the boundaries between professional and personal was inevitable. Frank answered my questions through her analysis of the effects of power in their relationship. She tells us the stories of some moments, which show the complexities of power inherent in their relationship. Power games become visible particularly in times of crisis when there is a disagreement between them on Frank's interpretations. Although she never denies that she has power over DeVries as the researcher, she also reveals the moments in which DeVries has the power over her. The consciousness of these two women on the nature of asymmetrical power between a researcher and a native enables them to discuss their positions and power relations. The dialogue between DeVries and Frank where DeVries expresses her experience of unequal power in their relationship, is one of the most impressive ones quoted in this book (p. 114). Frank lets us hear/read the interpretation of DeVries from a 'native' position thorough this dialogue. Frank's reflection on her tension in defining herself and/or being defined by DeVries as a 'researcher' or a 'friend' is an answer to the second part of my question. The boundaries between personal and professional are not always clear when you work together writing a biography. The possibility of crossing those boundaries is always there. Most importantly, the meanings Frank attributes to their individual positions in this research appear to be different from DeVries'. Her account underlines the necessity of self-reflection for all researchers on their position.

I responded to Frank who invited the reader of this cultural biography to reflect on her/his reading experience. I was astonished by the amazing courage of Diane DeVries in her lifelong resistance to the common cultural images of being 'disabled and woman'. I also thought that having multiple identities made her stronger in life although she was defined as 'disadvantaged' by cultural and institutional discourses. Besides, Frank's book shows how each individual life is political, and has the ability to make a difference in broader cultural, social and political processes. I would recommend you accepting Frank's invitation to self-reflection in your reading as well.

Cigdem Esin

doi: 10.1057/palgrave.fr. 9400332 